\title{
JUSTIÇA DISTRIBUTIVA: UMA REVISÃO DA LITERATURA PSICOSSOCIAL E DESENVOLVIMENTISTA
}

\author{
Leonardo Rodrigues Sampaio* \\ Cleonice P. Santos Camino ${ }^{\#}$ \\ Antonio Roazzi
}

\begin{abstract}
RESUMO. Justiça distributiva designa um construto relacionado à maneira como as pessoas avaliam as distribuições de bens positivos (renda, liberdade, cargos políticos) ou negativos (punições, sanções, penalidades) na sociedade. Ao fazer julgamentos distributivos, os indivíduos estão preocupados em avaliar em que medida a distribuição favoreceu ou prejudicou os envolvidos, a partir de parâmetros ou princípios que determinam qual método distributivo é mais ou menos justo aplicar no contexto da distribuição. A respeito da justiça distributiva, muitos estudos teóricos e empíricos têm sido realizados. O objetivo do presente trabalho é fazer uma revisão da literatura psicológica sobre o conceito de justiça distributiva, apresentando, inicialmente, as principais teorias psicossociais e do desenvolvimento que tratam deste tema. Além disso, alguns estudos empíricos importantes sobre a justiça distributiva serão revistos e discutidos. Por fim, são feitas algumas considerações a respeito do campo de estudos na atualidade.
\end{abstract}

Palavras-chave: Justiça distributiva; psicologia social; psicologia do desenvolvimento.

\section{DISTRIBUTIVE JUSTICE: A REVIEW OVER PSYCHOSOCIAL AND DEVELOPMENTAL LITERATURE}

\begin{abstract}
Distributive justice assigns a construct related to the way as the people evaluate the distributions of positive goods (income, freedom, positions politicians) or negatives ones (punishment, sanctions, penalties) in society. When making distributive judgments, the individuals are concerned if the distribution favored or it harmed the involved ones, using parameters or principles that determine which distributive method is more or less just of being applied in the context of the distribution. Related to the distributive justice, many theoretical and empirical studies have been carried through. The main aim of the present work is to make a revision of psychological literature regarding the concept of distributive justice. It will be presented the main psychosocial and developmental theories that deal with this subject. Then, some important empirical studies on distributive justice will be reviewed and criticized. Finally, some consideration about the field of nowadays studies will be made.
\end{abstract}

Key words: Distributive justice; social psychology; developmental psychology.

\section{JUSTICIA DISTRIBUTIVA: UNA REVISIÓN DE LA LITERATURA PSICOSOCIAL Y DE DESARROLLO}

\begin{abstract}
RESUMEN. Justicia distributiva designa un constructo relacionado a la manera como las personas evalúan las distribuciones de bienes positivos (renta, libertad, cargos políticos) o negativos (puniciones, sanciones, penalidades) en la sociedad. Al hacer juicios distributivos, los individuos están preocupados en evaluar en que medida la distribución favoreció o perjudicó los envueltos, a partir de parámetros o principios que determinan cual método distributivo es más o menos justo de ser aplicado en el contexto de la distribución. Con respecto a justicia distributiva, muchos estudios teóricos y empíricos han sido hechos. El objetivo del presente trabajo es hacer una revisión de la literatura psicológica acerca del concepto de justicia distributiva, presentando, inicialmente, las principales teorías psicosociales y de desarrollo que tratan de este tema. Además de eso, algunos estudios empíricos importantes sobre la justicia distributiva serán revistos y criticados. Por fin, serán hechas algunas consideraciones acerca del campo de estudios en la actualidad.
\end{abstract}

Palabras clave: Justicia distributiva; psicología social; psicología del desarrollo.

\footnotetext{
* Doutorado em Psicologia Cognitiva. Professor Adjunto I da Fundação Universidade Federal do Vale do São Francisco, Brasil.

\# Doutorado em Psicologia. Professor titular da Universidade Federal da Paraíba, Brasil.

II Doutorado em Psicologia do Desenvolvimento. Professor Associado I da Universidade Federal de Pernambuco, Brasil.
} 
Justiça distributiva designa um constructo relacionado à maneira como as pessoas avaliam as distribuições de bens positivos (renda, liberdade, cargos políticos) ou negativos (punições, sanções, penalidades) na sociedade. Ao fazer julgamentos distributivos, os indivíduos avaliam, a partir de parâmetros que determinam qual método distributivo é mais ou menos justo aplicar no contexto da distribuição, em que medida a distribuição favoreceu ou prejudicou os envolvidos.

A maneira como as pessoas aplicam princípios distributivos e a variabilidade ou não no uso destes princípios é uma questão que tem dividido os pesquisadores. Assim, no que diz respeito à pesquisa sociológica e psicossociológica, a justiça distributiva tem sido investigada empiricamente a partir de duas grandes abordagens: a unidimensional e a multidimensional (Assmar \& Ferreira; 2005; Dell'Aglio \& Hutz, 2001; Sabbagh, 2001). A abordagem unidimensional propõe a existência de princípios distributivos únicos, os quais são aplicados em toda e qualquer situação de distribuição. Por outro lado, a abordagem multidimensional defende a existência de diversos princípios (utilitaristas, equitativos ou benevolentes, por exemplo), os quais são aplicados isoladamente ou em conjunto, a depender da situação julgada.

Em geral perspectivas unidimensionais são limitadas, porque tendem a ser universalistas e a considerar que um só princípio é utilizado universalmente pelas pessoas para tomar decisões distributivas em diferentes situações. Por outro lado, abordagens multidimensionais tendem a particularizar os princípios e a vê-los como produto do contexto social no qual eles são evocados. Entre os autores da primeira abordagem destacam-se Homans e Adams e entre os da segunda destaca-se Morton Deutsch.

Seguindo o princípio aristotélico da "igualdade proporcional", Homans (1958) construiu uma teoria empiricamente orientada, chamada de Teoria da Equidade, a qual foi posteriormente desenvolvida por Adams (1965) e Walster, Berscheid e Walster (1973). A suposição inicial, e talvez a mais importante da teoria de Homans, é a de que a interação entre as pessoas deve ser compreendida como um tipo de troca de bens materiais ou não materiais, e que a justiça distributiva é um dos mecanismos pelos quais se pode garantir o equilíbrio e a justiça social.

Segundo Homans (1958), mesmo que haja diferenças entre as quantidades absolutas de recompensas recebidas por dois indivíduos, a justiça distributiva será alcançada se os lucros de ambos tenderem à igualdade proporcional, considerando-se os custos que cada um teve. Nesta direção, "se os custos dos membros de um grupo são maiores do que os de outro, a justiça distributiva requer que suas recompensas sejam também mais altas... [por outro lado,] se as recompensas são elevadas, os custos devem ser elevados também". (Homans, 1958, p. 604)

Com base neste pressuposto, Adams (1965) e Walster et al. (1973) propuseram a existência de um princípio distributivo (princípio da equidade), responsável por fazer com que as pessoas avaliem a questão da justiça distributiva a partir da comparação entre os outcomes recebidos e os inputs investidos por indivíduos de um mesmo grupo. Os outcomes correspondem a consequências positivas (recompensas) ou negativas (custos) decorrentes das relações interpessoais, e os inputs, às contribuições pessoais (esforço, trabalho, dinheiro etc.) que possibilitam gerar algum tipo de recompensa.

Apesar de esta teoria ter exercido importante papel no campo da Psicologia Social por mais de 20 anos, diversos autores (Damon, 1977, 1980; Deutsch, 1975; Sigelman \& Waitzman, 1991) questionaram o princípio da equidade, afirmando que ele refletia mais o pensamento econômico das sociedades ocidentais capitalistas do que uma estrutura cognitiva universal propriamente dita.

No que se refere ainda à questão da multidimensionalidade do construto da justiça distributiva, as pesquisas empiricamente orientadas têm como mais importante referencial a teoria de Deutsch (1975), que defende a existência de pelo menos três princípios distributivos - igualdade, necessidade e equidade -, que são usados de modos diferentes, a depender do contexto distributivo. Diversamente do princípio da equidade, o princípio da igualdade estabelece que os bens disponíveis na sociedade devem ser divididos em partes estritamente iguais; e o princípio da necessidade propõe que pessoas pobres, em situação de risco ou com poucas oportunidades, devem ser favorecidas e receber mais outcomes do que as demais.

Segundo Deutsch (1975), o tipo de relação interpessoal predominante, assim como os objetivos dos grupos sociais, determinam como as pessoas escolhem e aplicam princípios distributivos: se o aumento da produtividade for o objetivo principal, predominará a equidade; se a manutenção da harmonia grupal for tomada como muito importante, prevalecerá o igualitarismo; por fim, caso se considere importante promover o desenvolvimento e o bem-estar dos membros do grupo, haverá a tendência de prevalecer o princípio da necessidade. 
Além da dimensionalidade do construto, outro aspecto a ser considerado nos estudos sobre a justiça distributiva é o nível de análise a partir do qual se abordam os julgamentos distributivos. Segundo Assmar (2000), até a década de 80 havia predomínio de pesquisas voltadas para o estudo da chamada microjustiça. Neste nível, o foco recai sobre a preferência ou aplicação de princípios a situações nas quais existem pessoas específicas e com características pessoais que se tornam importantes para o processo de tomada de decisão distributiva. Assim, "qualquer princípio na forma 'para cada um de acordo com X', tais como as distribuições por necessidade ou esforço é um princípio de microjustiça." (Sabbagh, 2001, p. 239).

Apesar do pioneirismo de Deutsch (1975) em criticar o enfoque dado pelas abordagens unidimensionais à microjustiça, foi só no início da década de 90 que outro nível de análise começou a ser considerado pelos pesquisadores: o nível da macrojustiça. Como marco dessa mudança Assmar (2000) cita o trabalho Social Justice in Human Relations (Vermunt \& Steensma, 1991), no qual é discutida a noção de justiça a partir de três níveis: o individual, o grupal e o societal.

No primeiro nível, o foco está na análise sobre o conhecimento e compreensão dos processos de desenvolvimento relacionados à construção do sentido cognitivo da justiça, e nas reações individuais, à violação das normas. No nível grupal, busca-se compreender como os indivíduos distribuem recursos em situações de competição e/ ou cooperação, e como eles elaboram as regras de justiça. Além disto, há o interesse em "investigar a influência das relações intergrupais na construção de normas grupais de justiça e em estudar a interface entre as reações individuais e grupais a uma situação injusta" (Assmar, 2000, p. 501). Por fim, no nível societal, a ênfase está na análise da maneira como as pessoas concebem a justiça em situações de distribuição de bens e recompensas na sociedade como um todo.

De maneira geral, a diferença entre micro e macrojustiça diz respeito à avaliação sobre a aplicação dos princípios distributivos em diferentes contextos: se há preocupação com um sistema mais amplo (a sociedade, os países ou a humanidade), fala-se de macrojustiça; se os julgamentos referem-se a situações específicas, nas quais sobressaem as características de indivíduos particulares, está em jogo uma noção de microjustiça. Existe um amplo corpo de pesquisas demonstrando que as pessoas distinguem princípios de micro e de macrojustiça quando fazem e julgam distribuições, preferindo um ou outro princípio, a depender do contexto investigado (Assmar \& Ferreira, 2005; Barret-Howard \& Tyler, 1986; Skarzynska, 1989).

Mesmo considerando-se os avanços ocorridos no campo de estudos da justiça distributiva nos últimos 20 anos, as revisões de literatura feitas por Assmar (2000) e Sampaio (2007) indicam que, apesar de algumas teorias partilharem de uma visão mais ampla do fenômeno da justiça, na pesquisa empírica permanece o foco sobre o nível da microjustiça. Essas pesquisas têm buscado embasamento teórico, principalmente, nos estudos provenientes da Psicologia Social e da Psicologia do Desenvolvimento, alguns dos quais serão apresentados a seguir.

\section{TEORIAS PSICOSSOCIOLÓGICAS DA JUSTIÇA: PRESSUPOSTOS E EVIDÊNCIAS EMPÍRICAS}

Por muitos anos, o campo de estudos da chamada Psicologia da Justiça recebeu forte influência de quatro teorias, que enfatizavam a importância tanto de fatores estruturais (ligados à conjuntura social) quanto de fatores pessoais (ligados à motivação e às preferências individuais): a Teoria do Autointeresse, a Teoria da Crença num Mundo Justo, a Teoria da Atribuição e a Teoria da Ideologia. Ao longo dos anos, uma série de estudos forneceu forte suporte empírico para cada uma destas teorias, o que levou a sua consolidação dentro da Psicologia Social.

A Teoria do Autointeresse, proposta por autores como Sears e Funk (1991), considera que os indivíduos são materialistas, egocêntricos e estão buscando sempre maximizar o ganho pessoal. Assim, a percepção sobre a justiça dependeria de quanto as distribuições beneficiam ou prejudicam o self ou o grupo social do indivíduo ( $\mathrm{Ng} \&$ Allen, 2005). Diversas pesquisas (Batson et al., 1997; Batson et al., 1999; Nisan, 1984; Sampaio, 2007) dão suporte a esta teoria, demonstrando, por exemplo, que em pequenos grupos os indivíduos tendem a preferir normas distributivas que satisfaçam seus próprios interesses (quem produz mais prefere a equidade e quem produz menos considera a igualdade ou a necessidade mais justas).

Outras pesquisas (Cook \& Hegtvedt, 1983) indicam que o autointeresse também influencia a percepção de justiça distributiva em contextos amplos (sistema econômico), pois grupos com status elevado preferem regras equitativas, enquanto grupos com status baixo defendem uma maior transferência de recursos para as classes menos favorecidas, advogando a necessidade de aplicação de princípios 
baseados na benevolência ou na necessidade (Sampaio, 2007). Ademais, Skarzynska (1989) demonstrou que a percepção de justiça/injustiça é influenciada pela natureza (prejudicial ou benéfica) dos outcomes distribuídos e pela perspectiva avaliativa dos envolvidos (se eles são participantes ou apenas observadores externos da situação).

Os proponentes da Teoria da Crença no Mundo Justo, por sua vez, defendem que as pessoas têm necessidade de acreditar que a sociedade é estável e ordenada e que, geralmente, cada um recebe o que merece. Segundo Lerner e Miller (1978), o principal proponente desta teoria, desde as primeiras experiências de socialização as crianças são estimuladas a acreditar em algum tipo de "justiça do merecimento", o que as faz comportar-se "corretamente", mesmo sabendo que poderão receber recompensas apenas no futuro. É este tipo de crença que leva os adultos a submeterem-se aos contratos sociais (mesmo que estes os prejudiquem), às intempéries do dia-a-dia, e que consigam esperar a retribuição/pagamento por suas ações, mesmo quando isto implica em um prazo maior de tempo.

De acordo com os pressupostos dessa teoria, espera-se que, quando o indivíduo julgue ter havido ou estar ocorrendo algum tipo de injustiça com alguém, ele busque a restauração da justiça por meio de compensação (material ou psicológica) ou do convencimento de si mesmo de que a vítima merece o que lhe aconteceu, seja porque é mau-caráter, seja porque se envolveu em atos criminosos, descuidados ou tolos.

Alguns estudos empíricos ( $\mathrm{Ng} \&$ Allen, 2005) apoiam a teoria de Lerner, demonstrando que quanto maior a crença no mundo justo, maior a tendência a considerar que o sistema econômico é justo e a desenvolver atitudes negativas em relação a grupos desprivilegiados. Outros dados demonstram que as pessoas associam virtudes a outcomes favoráveis e vícios (preguiça, maldade ou falhas morais) a infortúnios sofridos, e que há uma relação entre a percepção que as pessoas têm dos outcomes distribuídos e a atribuição de culpa, responsabilidade ou merecimento por parte de quem recebe estes outcomes. (Lerner \& Miller, 1978; Cook \& Hegtvedt, 1983).

$\mathrm{Na}$ Teoria da Atribuição, o foco recai sobre a percepção que as pessoas têm a respeito das causas do comportamento social, assim como sobre a percepção que elas têm dos outros e de si mesmas no que diz respeito a habilidades, sentimentos, competências, etc. e sua relação com as causas dos fenômenos observados. Kelley (1973) afirma que esta teoria deve ser considerada epistemológica, pois investiga os processos que levam o homem a conhecer seu mundo e a 'saber que sabe', isto é, a ter um sentido de que suas crenças e julgamentos são verídicos.

Em linhas gerais, a Teoria da Atribuição pressupõe que uma atribuição causal consiste em imputar uma propriedade $\mathrm{X}$ qualquer a uma identidade Y e produzir explicações, julgamentos ou avaliações a partir desta associação. No dia-a-dia, as pessoas observam a realidade e constroem modelos correlacionais "ingênuos" para fazer inferências causais, ou seja, elas atribuem as causas de um determinado fenômeno aos fatores que variam junto com ele ao longo do tempo, a partir dos inputs informacionais disponíveis naquele momento.

Segundo mostram algumas pesquisas, quando as pessoas julgam que as causas de uma situação de infortúnio são decorrentes de fatores internos - como preguiça, desinteresse ou comodismo - os outcomes distribuídos tendem a ser considerados justos (Cook \& Hegtvedt, 1983); por outro lado, quando elas atribuem as causas da situação econômica a fatores externos como a conjuntura social, crises econômicas, falta de oportunidades etc. - há uma tendência a julgar que a distribuição foi injusta (Kelley, 1973; Ng \& Allen, 2005). Estes dados são pertinentes, pois evidenciam que as avaliações de justiça/ injustiça que as pessoas fazem cotidianamente dependem das explicações causais que elas constroem, o que reforça a Teoria da Atribuição.

Por fim, a Teoria da Ideologia defende que durante a socialização as pessoas internalizam valores, atitudes e comportamentos que são prescritivos por natureza e as predispõem a fazer diversos tipos de julgamento de justiça. Autores desta perspectiva enfatizam que as ideologias funcionam como esquemas de ação que dirigem o comportamento dos indivíduos, exercendo papel fundamental nas relações de poder dentro dos grupos humanos (Pratto, Tatar \& Conway-Lanz, 1999). Assim, o principal pressuposto da Teoria da Ideologia é que os valores e crenças transmitidos culturalmente tendem a guiar e a legitimar o comportamento social.

Ao discutirem a questão da justiça a partir dessa ótica, Pratto et al. (1999) afirmam que princípios distributivos não são estruturas cognitivas que simplesmente surjem nas mentes das pessoas por efeito do desenvolvimento; ao contrário, são esquemas que refletem a aprendizagem de modelos de comportamento e julgamento construídos em contextos socioculturais específicos, portanto são produtos da ideologia predominante em determinados grupos sociais. 
Pratto et al. (1999) demonstraram empiricamente que, em grupos que valorizam a competitividade, a individualidade e a distribuição desigual de poder, os indivíduos consideravam distribuições equitativas como muito justas, produziam mais justificativas baseadas no princípio da equidade e tendiam a favorecer partes mais produtivas em dilemas distributivos. Por outro lado, em grupos nos quais tais valores não eram predominantes, as pessoas julgavam mais justo distribuir os outcomes em função da necessidade das pessoas, usavam mais justificativas baseadas no princípio da necessidade e favoreciam partes mais pobres, em situações de dilema distributivo.

As teorias do Autointeresse, da Crença num Mundo Justo, da Atribuição e da Ideologia foram muito importantes no âmbito da Psicologia Social e orientaram, hegemonicamente, o campo de estudos da chamada Psicologia da Justiça por vários anos. Nos últimos 30 anos, constituiu-se um amplo corpo de pesquisas que corrobora os principais pressupostos de cada um destes modelos teóricos, demonstrando a importância de variáveis sociocognitivas para os julgamentos distributivos.

Todavia, ressalta-se que desde o trabalho seminal de Piaget (1932/1994) sobre os julgamentos morais infantis, diversos autores têm investigado a transformação das concepções de justiça distributiva ao longo dos anos e os fatores do desenvolvimento envolvidos neste processo. Além de Piaget, William Damon também propôs um modelo teórico de desenvolvimento das noções de justiça que tem servido de inspiração para pesquisas que abordam os julgamentos distributivos infantis a partir de uma visão psicogenética.

\section{TEORIAS DO DESENVOLVIMENTO DA JUSTIÇA DISTRIBUTIVA: PIAGET E DAMON}

Em seu livro O Juízo Moral da Criança (1932/1994), Piaget observou a existência de três períodos evolutivos na noção de justiça distributiva: no primeiro (cinco aos sete anos de idade) o comportamento infantil refletia os efeitos da coação adulta, havia a predominância de uma noção de retribuição baseada no respeito unilateral e na obediência, e as crianças defendiam que a distribuição mais justa era aquela que estivesse de acordo com as determinações estabelecidas por figuras de autoridade.

$\mathrm{Na}$ segunda etapa (entre 8 e 12 anos de idade), havia uma predileção pelo igualitarismo absoluto e as crianças defendiam que a justiça consiste em distribuir todos os tipos de bens, benefícios ou punições em partes exatamente iguais, buscando garantir que ninguém fosse prejudicado e que todos saíssem satisfeitos com a divisão.

Por outro lado, Piaget (1932/1994) observou que a partir dos doze anos de idade havia uma tendência das crianças a utilizar um princípio equitativo, no qual as condições e características individuais das pessoas envolvidas na distribuição eram consideradas muito importantes na hora de tomar decisões distributivas. Neste caso, a equidade não buscava privilegiar uns em detrimento de outros, mas objetivava tornar a igualdade mais efetiva, através da análise e ponderação cuidadosa das questões pessoais relevantes (Piaget, 1932/1994, p. 238).

No que diz respeito especificamente à questão da equidade, Piaget (1954/2001) julga que esta só se torna possível a partir do desenvolvimento da reversibilidade lógica e do sentimento de reciprocidade: a primeira permite que o indivíduo seja capaz de ponderar/avaliar diferentes perspectivas e de fazer reverter mentalmente qualquer tipo de ação, enquanto a reciprocidade impõe o desejo de que haja tratamento igualitário e respeito mútuo entre as pessoas.

Apesar de ter observado a ocorrência de mudanças significativas nos julgamentos morais das crianças ao longo da infância, Piaget (1932/1994) considerou que seus dados eram insuficientes para ele poder falar em estágios de desenvolvimento bem delimitados. Neste sentido, a predominância de um princípio distributivo em determinada faixa etária poderia não significar, necessariamente, que a preferência por tal princípio deveria ser sempre esperada naquele nível de desenvolvimento. Ademais, o próprio Piaget não investigou se os resultados obtidos em suas investigações com crianças genebresas eram replicáveis em outras amostras.

Tomando como base os trabalhos de Piaget (1932/1994), William Damon investigou, sistematicamente, como os julgamentos distributivos transformam-se da infância até a adolescência. Além de constatar uma sequência evolutiva nas noções infantis sobre a justiça, esse autor observou que crianças bem novas (por volta dos três anos de idade) já eram capazes de avaliar questões sociais e de emitir julgamentos morais utilizando critérios que estavam além do respeito unilateral, próprio da fase de heteronomia moral (Damon, 1977; 1980). Com base nesses resultados, Damon propôs uma tipologia com seis níveis que caracterizam a evolução da justiça distributiva e afirmou ser necessário considerar a existência, entre as crianças pequenas, de uma sofisticação moral maior do que a que foi proposta por Piaget. 
De acordo com o modelo de Damon (1980), nos dois primeiros níveis de desenvolvimento os julgamentos de justiça são produtos do desejo de que algo aconteça, e baseiam-se em observações da realidade externa e de características dos envolvidos na distribuição. No terceiro e quarto níveis a igualdade é vista como preventiva de queixas, disputas e outros tipos de conflito; surgem considerações a respeito da importância da reciprocidade, e questões de mérito passam a ser importantes para os julgamentos distributivos. Por fim, nos últimos dois níveis surge a noção de equidade e desenvolve-se a compreensão de que a justiça pode ser relativa e depender das circunstâncias e das pessoas envolvidas em cada situação.

De maneira geral, as pesquisas de Damon (1977, 1980) indicam que as crianças são capazes de ponderar sobre questões sociais, avaliar argumentos morais e fazer julgamentos sobre justiça distributiva mesmo em idades tenras; porém é preciso lembrar que os estudos de Damon utilizaram apenas situações de distribuição de prêmios, não incluindo outros tipos de outcomes. Numa situação cotidiana de crianças pequenas, a experiência mais comum seria a de divisão de brinquedos ou do lanche, ao invés de prêmios. Ademais, as amostras investigadas por Damon foram compostas apenas por estadunidenses, $\mathrm{O}$ que pode ter ocasionado vieses culturais em seus resultados (Sigelman \& Waitzman, 1991).

Uma vez que a moralidade constitui-se nas interações das crianças com seus pares e com os adultos e supõe a reconstrução pessoal dos valores e normas presentes nos diferentes grupos, é razoável pensar que a noção de justiça poderia variar de grupo para grupo, o que corroboraria alguns pressupostos das teorias psicossociais. Por outro lado, se isto de fato ocorresse, não excluiria a possibilidade de que os mecanismos cognitivos/afetivos responsáveis por esse processo de reconstrução fossem comuns a todos os indivíduos, o que apontaria para a necessidade de também se investigarem os aspectos do desenvolvimento envolvidos nesse processo de construção. A seguir, far-se-á uma revisão de estudos empíricos que mostram a influência de aspectos psicossociais nos julgamentos distributivos e de outros estudos que explicitam como os julgamentos distributivos se desenvolvem na infância.

\section{ESTUDOS EMPÍRICOS}

\section{Influência de aspectos psicossociais}

Leventhal e Lane (1970) demonstraram que, em situações de trabalho em dupla, nas quais os participantes podiam decidir como outcomes poderiam ser divididos, os homens pegavam maior quantidade de recompensas para si mesmos, independentemente de seu desempenho, e que, mais do que as mulheres, utilizavam a produtividade como critério mais forte para regular a divisão. As mulheres, por outro lado, quando tinham performance superior à dos seus parceiros, pegavam pouco mais do que a metade das recompensas, e quando tinham performances inferiores, pegavam porções bem menores do que aquelas pegas por homens com performance inferior.

Jackson, Messe e Hunter (1985) afirmam que, apesar de o estudo de Leventhal e Lane (1970) e outras pesquisas sugerirem a existência de diferenças no comportamento distributivo de homens e mulheres, estudos em que os parceiros são de diferentes sexos não produziram resultados conclusivos e que alguns parecem indicar uma influência maior do gênero do que do sexo propriamente dito. Nesta direção, estes autores desenvolveram um estudo no qual constataram um efeito significativo do gênero do cotrabalhador sobre o comportamento distributivo (as parceiras mulheres receberam mais dinheiro do que os parceiros masculinos), mas não observaram efeitos nem do sexo nem do gênero do alocador sobre os bônus distribuídos.

Os autores do presente trabalho julgam que, de uma maneira geral, os dados de pesquisa que apontam a existência de diferenças nos julgamentos distributivos relacionadas ao sexo e ao gênero podem ser decorrentes dos diferentes papéis atribuídos a homens e mulheres e da percepção sobre feminilidade e masculinidade prevalente nas sociedades investigadas nestes estudos. Nesse sentido, é possível que as mulheres sejam vistas como benevolentes e altruístas, e os homens, por sua vez, como competitivos e individualistas, e que esse tipo de concepção implique em diferentes noções de justiça.

Considerando a necessidade de investigar se o tipo de relacionamento interpessoal influenciava as decisões distributivas das pessoas, Lamm e Schwinger (1980) realizaram uma pesquisa com jovens alemães utilizando uma situação experimental na qual dois personagens produziam juntos e vendiam um manuscrito para comprar livros de que precisavam. Os participantes eram informados de que os personagens haviam trabalhado igualmente, mas que um (personagem A) precisava de $200 \mathrm{MD}$ e o outro (personagem B) precisava de apenas $50 \mathrm{MD}$, e que a venda do manuscrito havia rendido uma quantidade de $300 \mathrm{MD}$, os quais deveriam ser divididos entre A e B. Havia duas variações no tipo de relacionamento 
interpessoal entre A e B: eram amigos, ou apenas mantinham um relacionamento superficial.

Nos resultados, Lamm e Schwinger (1980) observaram que o personagem A recebeu maior quantidade de MD em todas as situações experimentais, mas que ele foi mais favorecido na situação em que os personagens eram amigos. Análises de variância demonstraram ter havido interação entre o tipo de relacionamento interpessoal dos personagens e o sexo dos respondentes, pois na situação na qual A e B relacionavam-se apenas superficialmente, as mulheres distribuíram mais igualitariamente que os homens.

Peterson (1975) utilizou um delineamento no qual manipulou o grau de relacionamento entre personagens de um dilema hipotético (pai e filho x um adulto e um garoto que não se conheciam) e a necessidade de um deles (o garoto era mais necessitado $x$ não se fazia nenhuma menção à necessidade dos personagens), para verificar a influência dessas duas variáveis sobre o comportamento distributivo. Análises de variância indicaram influência significativa do tipo de relacionamento entre os personagens (quando eles eram estranhos, o homem recebeu mais do que quando eram pai e filho); da necessidade (quando não se fazia menção à necessidade o adulto recebeu mais do que quando se dizia que a criança precisava de mais dinheiro) e uma interação entre necessidade e relacionamento (o princípio da necessidade foi mais frequentemente utilizado quando os personagens eram familiares).

Outros autores desenvolveram estudos transculturais e compararam as decisões distributivas de pessoas de diferentes países. Em um destes estudos, Giacobbe-Miller, Miller e Victorov (1998) criaram uma situação de role-play e constataram que administradores estadudinenses e russos consideravam a produtividade um fator muito importante na hora de distribuir bônus entre empregados, mas apenas os russos levavam em conta também o nível de necessidade dos envolvidos na situação de distribuição e outros fatores, como o relacionamento interpessoal no ambiente de trabalho.

$\mathrm{O}$ que se pode concluir destes resultados de pesquisa é que fatores situacionais são de suma importância para os julgamentos sobre justiça distributiva, especialmente no que se refere ao tipo de relacionamento interpessoal dos envolvidos e aos valores presentes na cultura dos entrevistados. Nesta direção, alguns resultados citados anteriormente corroboram os pressupostos de Deutsch (1975) e de outras teorias psicossociológicas da justiça distributiva.

\section{Desenvolvimento da justiça distributiva}

Considerando algumas críticas feitas ao método adotado por Damon (1980) em suas pesquisas, Sigelman e Waitzman (1991) elaboraram um estudo que buscava investigar em que idade as informações situacionais eram utilizadas pelas crianças como parâmetros para suas decisões distributivas. De maneira geral, os resultados desta pesquisa demonstraram que crianças mais velhas (9 a 10 anos) foram mais flexíveis em suas respostas e aplicaram diferentes princípios ao resolver dilemas distributivos. Por outro lado, as crianças mais novas (5 a 6 anos) optaram por distribuir de maneira igualitária em todas as situações experimentais, o que sugere que as informações contextuais fornecidas nos dilemas não influenciavam suas decisões.

A pesquisa de Sigelman e Waitzman (1991) destaca-se ainda por demonstrar como a capacidade de articular diferentes pontos de vista é fundamental para a evolução da justiça distributiva. Nesse estudo, evidenciou-se que, enquanto as crianças mais novas pareceram não ter atentado para as diferenças nas características dos personagens, as mais velhas determinaram o que era mais justo avaliando os diversos tipos de informação presentes nas situações distributivas.

No Brasil, Sales (2000) desenvolveu um estudo com crianças de diferentes idades, no qual narrava a história de personagens que haviam recolhido latas de cerveja para serem vendidas. Nos resultados dessa pesquisa, Sales observou que as crianças mais velhas distribuíram o dinheiro arrecadado usando o princípio da equidade, enquanto as mais novas preferiram seguir as sugestões dadas pela professora, o que evidenciava os efeitos da heteronomia moral sobre estas crianças, corroborando o que foi proposto nas teorias de Piaget (1932/1994) e Damon (1980).

Destaca-se também o estudo conduzido por Dell'Aglio e Hutz (2001) com crianças brasileiras cujas idades variavam entre 5 a 14 anos. Estes pesquisadores solicitavam que os participantes distribuíssem doces entre dois personagens que haviam pintado quadros juntos, sendo que havia diferenças quantitativas e qualitativas na produção dos dois. Além disto, pediam que as crianças julgassem as distribuições (igualitária ou equitativa) que a professora dos personagens havia feito. De maneira geral, Dell' Aglio e Hutz (2001) observaram que as crianças mais novas (5 a 6 anos) seguiam, irrestritamente, a distribuição da professora (respeito 
pela autoridade), que as crianças de 9 a 10 anos mostravam uma predileção pelo princípio da igualdade e que as mais velhas escolhiam, sobretudo, a equidade como princípio distributivo mais justo.

Objetivando investigar se os valores da cultura chinesa influenciam os julgamentos distributivos de crianças daquele país, Wong e Nunes (2003) realizaram um estudo no qual solicitavam que os participantes dividissem brinquedos entre personagens que se encontravam para brincar no pátio da escola. Para tanto, utilizaram uma situação hipotética com um dilema versando sobre dois personagens que deveriam decidir dar ou não mais blocos a outros que chegavam atrasados ao playground da escola, sendo que havia variações nas características dos que chegavam depois: um era mal-educado, outro gentil e o terceiro era mais jovem que os demais.

Nos resultados, Wong e Nunes (2003) observaram que, de uma maneira geral, as crianças foram sensíveis à variação na idade, mas não ao comportamento (ser gentil ou ser mal-educado) dos outros personagens atrasados, pois o personagem mais novo recebeu uma quantidade de blocos superior à quantidade dada para os outros. Além disto, constataram que as crianças contaram os dois personagens que haviam chegado antes como uma única unidade de alocação e que apenas quando os três chegavam ao mesmo tempo é que eles eram contados como unidades independentes.

Em uma replicação da pesquisa de Wong e Nunes (2003) com uma amostra de crianças brasileiras, Sampaio, Camino e Roazzi (2007) utilizaram um delineamento transversal, a fim de verificar se havia evolução dos julgamentos distributivos infantis entre os cinco e os dez anos de idade. Nos resultados, constataram que as crianças utilizaram diferentes tipos de justificativa para sua distribuição e que questões relacionadas ao mérito puderam ser observadas mesmo nas respostas das mais novas. Além disto, observaram que as quantidades de blocos distribuídas pelas crianças de cinco e seis anos de idade não variaram significativamente ao longo das situações experimentais, indicando que as mais novas utilizaram um tipo de igualitarismo que as levou a julgar todos os personagens merecedores do mesmo tratamento. Por outro lado, as crianças de nove e de dez anos distinguiram os personagens e deram mais blocos ao personagem mais jovem e ao personagem gentil que ao mal-educado.

Os estudos de Sales (2000), Dell'Aglio e Hutz (2001), Sigelman e Waitzman (1991), Wong e Nunes (2003), e Sampaio et al. (2007) corroboram as teses de Piaget (1932/1994) e Damon (1980) de que a justiça distributiva segue um curso de desenvolvimento que parte do raciocínio retributivo e do respeito unilateral heterônomo, passa pelo igualitarismo absoluto e se dirige à equidade. $\mathrm{O}$ fato de esta evolução estar ligada aos avanços na idade indica que habilidades cognitivas, como o role-taking, desempenham importante papel na transformação da noção de justiça distributiva, visto que uma visão ampliada dos membros da sociedade possibilita que o indivíduo alcance formas superiores de equilíbrio nos raciocínios morais.

Um fato importante a ser mencionado é que, nas pesquisas citadas anteriormente, observou-se uma sequência de desenvolvimento dos raciocínios distributivos semelhante àquela investigada por Piaget (1932/1994); contudo, o que foi denominado de equidade em alguma destas pesquisas alinha-se mais com as ideias de Adams (1965) do que com os pressupostos piagetianos, pois os pesquisadores analisaram julgamentos baseados, sobretudo, na produtividade e merecimento dos envolvidos nas situações experimentais.

\section{CONSIDERAÇÕES FINAIS}

$\mathrm{Na}$ Psicologia, as principais teorias sobre a justiça são oriundas de duas grandes áreas: a Psicologia Social e a Psicologia do Desenvolvimento. Não obstante, julga-se que ainda são poucas as tentativas de articular os conhecimentos produzidos nestes dois campos, pois, por um lado, os psicólogos do desenvolvimento focalizam a influência de aspectos cognitivos, e por outro os psicólogos sociais enfatizam o papel de fatores contextuais e socioculturais nos julgamentos de justiça distributiva.

Destaca-se que a maior parte das pesquisas produzidas até o momento focalizou, sobretudo, os níveis de análise individual e interpessoal, deixando uma grande lacuna teórico-empírica nos níveis intergrupal e societal da justiça distributiva. Neste sentido, julga-se que pesquisas futuras devem preocupar-se não só com o papel dos processos cognitivo-afetivos envolvidos na elaboração dos princípios de justiça, mas também com as dinâmicas interacionais e valores presentes nos diferentes grupos socioculturais. Concorda-se com a consideração de Assmar (2000) de que a criação de estratégias de pesquisa que articulem os diferentes níveis de análise da justiça contribuirá muito para o desenvolvimento teórico-conceitual desta área e que tal atitude é necessária para o crescimento qualitativo no campo de estudos da justiça distributiva. 
Apesar de se considerar a importância da teoria de Adams (1965) para a compreensão da justiça distributiva, as pesquisas, cada vez mais, têm corroborado modelos multidimensionais, evidenciando que o princípio da equidade é apenas um dentre os muitos que podem ser utilizados cotidianamente pelas pessoas. Aliás, como visto anteriormente, em alguns contextos, esse princípio pode ser considerado pouco justo, e até injusto, quando comparado a outros.

Ainda no que se refere à questão da equidade, fazse necessário ressaltar a importância de que pesquisas futuras trabalhem no refinamento desse conceito, investigando se as pessoas usam, além dos dados sobre produtividade e necessidade, outros tipos de informações contextuais quando fazem julgamentos distributivos, e como o fazem. Sugere-se ainda que sejam investigados contextos que envolvam a distribuição de diversos tipos de outcome, como oportunidades profissionais e cargos políticos. Por exemplo, a polêmica atual envolvendo as cotas nas universidades públicas brasileiras pode servir como um bom tema de investigação sobre as avaliações da macrojustiça distributiva no Brasil.

Por fim, indica-se que pesquisas futuras investiguem como os julgamentos de justiça, o comportamento distributivo e o desenvolvimento sociomoral estão relacionados, pois, como indica a pesquisa de Skarzynska (1989), o que algumas pessoas consideram justo para os outros, nem sempre é visto como justo para elas mesmas. Ademais, existem situações nas quais as pessoas vinculam a noção de justiça ao seu próprio benefício, ou ao benefício do seu grupo social (Cook \& Hegtvedt, 1983; Sampaio, 2007), o que aponta a existência de julgamentos fortemente enviesados pelos interesses pessoais. Neste sentido, acredita-se que a investigação mais aprofundada desses fatos tenha muito a colaborar para compreensão das dinâmicas envolvidas na vida social, especialmente em um país como o nosso, marcado por tantas injustiças.

\section{REFERÊNCIAS}

Adams, J. S. (1965). Inequity in social exchange. In L. Berkowitz (Ed.), Advances in experimental social psychology (pp. 267-299). New York: Academic Press.

Assmar, E. M. L. (2000). A Psicologia Social e o estudo da justiça em diferentes níveis de análise. Psicologia: Reflexão e Crítica, 13(3), 497-506.

Assmar, E. M. L. \& Ferreira, M. C. (2005). Justiça organizacional: uma revisão crítica da literatura. Psicologia: Reflexão e Crítica, 18(3), 443-453.
Barret-Howard, E. \& Tyler, T.R. (1986). Procedural justice as criterion in allocation decisions. Journal of Personality and Social Psychology, 50(2), 296-304.

Batson, C. D., Kobrynowicz, D., Dinnerstein, J. L., Kampf, H. C. \& Wilson, A. D. (1997). In a very different voice: unmasking moral hypocrisy. Journal of Personality and Social Psychology, 72(6), 1335-1348.

Batson, C. D., Thompson, E., Seuferling, G., Whitney, H. \& Strongman, J. A. (1999). Moral Hypocrisy: appearing moral to oneself without being so. Journal of Personality and Social Psychology, 77(3), 525-537.

Cook, K.S. \& Hegtvedt, K. A. (1983). Distributive Justice, equity and equality. Annual Review of Sociology, 9, 217241.

Damon, W. (1977). The social word of the child. San Francisco: Jossey-Bass.

Damon, W. (1980). Patterns of change in children's social reasoning: A two-year longitudinal study. Child Development, 51, 1010-1017.

Deutsch, M. (1975). Equity, equality, and need: what determines which value will be used as the basis of distributive justice. Journal of Social Issues, 31(3), 137149.

Dell'Aglio, D. D. \& Hutz, C. S. (2001). Padrões evolutivos na utilização dos princípios de justiça distributiva em crianças e adolescentes no sul do Brasil. Psicologia: Reflexão $e$ Crítica, 24(1), 97-106.

Giacobbe-Miller, J. K., Miller, D. J. \& Victorov, V. I. (1998). A comparison of Russian and U.S. pay allocation decision, distributive justice judgments and productivity under different payment conditions. Personnel Psychology, 1(27), 137-154.

Homans, G. C. (1958). Social Behavior as exhange. American Journal of Sociology, 62, 597-606.

Jackson, L. A., Messe, L. A. \& Hunter, J.E. (1985). Gender role and distributive justice behavior. Basic and Applied Psychology, 6(4), 329-343.

Kelley, H. H. (1973). The process of causal attribution. American Psychologist, 28, 107-128.

Lamm, H. \& Schwinger, T. (1980). Norms concerning distributive justice: are needs taken into consideration in allocation decisions? Social Psychology Quarterly, 43(4), 425-429.

Lerner, M. J. \& Miller, D. T. (1978). Just World Research and the attribution process: looking back and ahead. Psychological Bulletin, 85(5), 1030-1051.

Leventhal, G. S. \& Lane, D. W. (1970). Sex, age, and equity behavior. Journal of Personality and Social Psychology, 15(4), 312-316.

Ng, S. H. \& Allen, M. W. (2005). Perception of economic distributive justice: exploring leading theories. Social Behavior and Personality, 33(5), 435-454.

Nisan, M. (1984). Distributive justice and social norms. Child Development, 55, 1020-2029. 
Peterson, C. C. (1975). Distributive justice within and outside the family. Journal of Psychology, 90, 123-127.

Piaget, J. (1994). O juízo moral na criança. $2^{a}$ ed. São Paulo: Summus. (Original publicado em 1932).

Piaget, J. (2001). Inteligencia y Afectividad. Buenos Aires: Aique. (Original publicado em 1954).

Pratto, F., Tatar, D. G. \& Conway-Lanz, S. (1999). Who gets what and why: determinants of social allocations. Political Psychology, 20(1), 127-150.

Sabbagh, C. (2001). A taxonomy of normative and empirically oriented theories of distributive justice. Social Justice Research, 14(3), 237-263.

Sales, E. M. B. (2000). O conceito de justiça distributiva relacionado às normas sociais escolares. Psicologia Reflexão e Crítica, 13(1), 49-58.

Sampaio, L. R. (2007). Produtividade, necessidade e empatia: relações entre julgamentos distributivos, consideração empática e tomada de perspectiva. Tese de Doutorado não publicada. Programa de Pós-graduação em Psicologia Cognitiva, Universidade Federal de Pernambuco, Recife.

Sampaio, Camino \& Roazzi (2007). Justiça distributiva em crianças de 5 a 10 anos de idade. Psicologia: Reflexão $e$ Crítica, 20(2), 195-202.
Sears, D. O. \& Funk, C. L. (1991). The role of self-interest in social and political attitudes. Advances in Experimental Social Psychology, 24, 1-91.

Sigelman, C. K. \& Waitzman, K. A. (1991). The development of distributive justice orientations: contextual influences on children's resource allocations. Child Development, 62, $1367-1378$

Skarzynska, K. (1989). Evaluative perspective and distributive justice. In: Eisenberg, N., Roykowsky, J., Staub, E. (Org.). Social and moral values: individual and societal perspectives (pp.139-152). Hillsdale: Lawrence Erlbaum.

Vermunt, R. \& Steensma, H. (1991). Social justice in human relations: Societal and psychological origins of justice. New York: Plenum.

Walster, E., Berscheid, E. \& Walster, G. W. (1973). New directions in equity research. Journal of Personality and Social Psychology, 25(2), 151-176.

Wong, M. M. A. \& Nunes, T. (2003). Hong Kong children's concept of distributive justice. Early Child Development and Care, 173(1), 119-129.

Recebido em 14/05/2008 Aceito em 06/08/2009

Endereço para correspondência : Leonardo Sampaio. Universidade Federal do Vale do São Francisco - UNIVASF. Colegiado de Psicologia. Av. José de Sá Maniçoba, s/n. Centro, CEP: 56304-250, Petrolina-PE. Brasil. E-mail: leorsampaio@yahoo.com.br 